\title{
Association Between Visual Impairment and Income Change: A Longitudinal Follow-up Study With a National Health Screening Cohort
}

\section{Hyo Geun Choi}

Hallym University College of Medicine, Hallym University Sacred Heart Hospital

Min Joung Lee

Hallym University College of Medicine, Hallym University Sacred Heart Hospital

Sung Uk Baek ( $\sim$ postharuto@hanmail.net )

Hallym University College of Medicine, Hallym University Sacred Heart Hospital

\section{Research Article}

Keywords: visual impairment, income, longitudinal analysis, national cohort

Posted Date: May 19th, 2021

DOI: https://doi.org/10.21203/rs.3.rs-530551/v1

License: @ (i) This work is licensed under a Creative Commons Attribution 4.0 International License. Read Full License 


\section{Abstract}

We evaluated the influence of visual impairment $(\mathrm{VI})$ on income change using the longitudinal database of a Korean National Health Insurance Service cohort. A total of 5,292 participants $\geq 40$ years old and registered as visually impaired persons were selected at a 1:4 ratio with 45,081 controls matched for age, sex, and income level. The income level of both the $\mathrm{VI}$ and control groups increased over time. In the VI group, the income levels 3, 4 and 5 years were higher than the initial value, while the income levels from 1 through 5 years were increased each year in the control group. The rate of change in income between time and VI were significant. In the subgroup analysis considering age, sex, and severity of $\mathrm{VI}$, the rate of change in income were significant in $<65$ years old subgroups. Regarding the severity of $\mathrm{VI}$, a significant interaction was found for the mild-to-moderate $\mathrm{VI}$ subgroup. Although both the $\mathrm{VI}$ and control groups showed increased income levels over 5 years, the degree of income increase in the VI group was relatively lower than that in the control group. This finding was prominent in the middle-age subgroup. These results strongly suggested that VI induced an income inequality.

\section{Introduction}

Visual impairment (VI), including blindness, is a serious disability that has a strong impact on quality of life. In particular, VI is well-known to be associated with lower socioeconomic status (SES) ${ }^{1-6}$. A relationship between $\mathrm{VI}$ and income level has been reported in diverse studies ${ }^{2-5}$; the results, varying between non-significant and significant associations, implicate a complex link between the two factors.

It is frequently asserted that $\mathrm{VI}$ is both a consequence and a cause of low income ${ }^{3,5-7}$. Whereas some evidence suggests that low income is a major barrier to uptake of ophthalmologic care and leads to lower medical compliance ${ }^{8-}$

10 , other evidence indicates that VI reduces the earning potential of impaired patients and/or the household members who care for them 7,11 .

Due to the multifactorial nature of social-economic status, identification of factors affecting income level is non-trivial, and certainly, there are numerous confounding factors that need to be considered and controlled for $1,3,12$. In this respect, the majority of previous studies' cross-sectional design is a limiting factor, as it does not allow for analysis of any temporal relationship between visual impairment and income change ${ }^{1,4,13-16}$. In order to clarify the association between these two factors, a longitudinal study design with a large population-based database is required.

A comprehensive understanding of the link between $\mathrm{VI}$ and income can be utilized to make socioeconomic policy that effectively supports people with VI. Furthermore, it might help to break the social and personal links between those two factors. The current study's purpose was to evaluate Vl's impact on longitudinal income change. To this end, changes in the income levels of $\mathrm{VI}$ and control groups in a representative sample cohort dataset of the Korean National Health Insurance Service (KNHIS) were followed annually for 5 years. The groups' initial income levels and demographic factors were matched, and additionally, subgroup analyses according to age, sex, and severity of VI were performed.

\section{Results}


Table 1

General Characteristics of Participants

\begin{tabular}{|c|c|c|c|}
\hline \multirow[t]{2}{*}{ Characteristics } & \multicolumn{3}{|l|}{ Total participants } \\
\hline & Visual impairment (n, \%) & Control (n, \%) & P-value \\
\hline Age (years old) & & & 1.000 \\
\hline $40-44$ & $351(7.4)$ & $1,404(7.4)$ & \\
\hline $45-49$ & $504(10.6)$ & $2,016(10.6)$ & \\
\hline $50-54$ & $668(14.0)$ & $2,672(14.0)$ & \\
\hline $55-59$ & $804(16.9)$ & $3,216(16.9)$ & \\
\hline $60-64$ & $895(18.8)$ & $3,580(18.8)$ & \\
\hline $65-69$ & $698(14.7)$ & 2,792 (14.7) & \\
\hline $70-74$ & $493(10.4)$ & $1,972(10.4)$ & \\
\hline $75-79$ & $253(5.3)$ & $1,012(5.3)$ & \\
\hline $80-84$ & $84(1.8)$ & $336(1.8)$ & \\
\hline $85+$ & $8(0.2)$ & $32(0.2)$ & \\
\hline Sex & & & 1.000 \\
\hline Male & $2,917(61.3)$ & $11,668(61.3)$ & \\
\hline Female & $1,841(38.7)$ & 7,364 (38.7) & \\
\hline Income (range categories) & & & 1.000 \\
\hline 0 (lowest) & $104(2.2)$ & $416(2.2)$ & \\
\hline 1 & $490(10.3)$ & $1,960(10.3)$ & \\
\hline 2 & $377(7.9)$ & $1,508(7.9)$ & \\
\hline 3 & $411(8.6)$ & $1,644(8.6)$ & \\
\hline 4 & $448(9.4)$ & $1,792(9.4)$ & \\
\hline 5 & $412(8.7)$ & $1,648(8.7)$ & \\
\hline 6 & $474(10.0)$ & $1,896(10.0)$ & \\
\hline 7 & $396(8.3)$ & $1,584(8.3)$ & \\
\hline 8 & $447(9.4)$ & $1,788(9.4)$ & \\
\hline 9 & $569(12.0)$ & $2,276(12.0)$ & \\
\hline 10 (highest) & $630(13.2)$ & 2,520 (13.2) & \\
\hline Region of residence & & & 1.000 \\
\hline Urban & $1,908(40.1)$ & $7,632(40.1)$ & \\
\hline Rural & $2,850(59.9)$ & $11,400(59.9)$ & \\
\hline Obesity † & & & \\
\hline
\end{tabular}




\begin{tabular}{|c|c|c|c|}
\hline Characteristics & Total participants & & \\
\hline Underweight & $141(3.0)$ & $621(3.3)$ & 0.165 \\
\hline Normal & $1,637(34.4)$ & $6,764(35.5)$ & \\
\hline Overweight & $1,314(27.6)$ & $5,133(27.0)$ & \\
\hline Obese I & $1,524(32.0)$ & 6,037 (31.7) & \\
\hline Obese II & $142(3.0)$ & $477(2.5)$ & \\
\hline Smoking status & & & 0.362 \\
\hline Nonsmoker & $3,258(68.5)$ & $12,891(67.7)$ & \\
\hline Past smoker & $459(9.7)$ & $1,795(9.4)$ & \\
\hline Current smoker & $1,041(21.9)$ & $4,346(22.8)$ & \\
\hline Alcohol consumption & & & $<0.001 *$ \\
\hline$<1$ time a week & $3,498(73.5)$ & $13,527(71.1)$ & \\
\hline$\geq 1$ time a week & $1,260(26.5)$ & $5,505(28.9)$ & \\
\hline Systolic blood pressure & & & 0.117 \\
\hline$<120 \mathrm{mmHg}$ & $1,132(23.8)$ & $4,705(24.7)$ & \\
\hline $120-139 \mathrm{mmHg}$ & $2,125(44.7)$ & $8,602(45.2)$ & \\
\hline$\geq 140 \mathrm{mmHg}$ & $1,501(31.6)$ & $5,725(30.1)$ & \\
\hline Diastolic blood pressure & & & $0.039 *$ \\
\hline$<80 \mathrm{mmHg}$ & $1,759(37.0)$ & $7,173(37.7)$ & \\
\hline $80-89 \mathrm{mmHg}$ & $1,662(34.9)$ & $6,856(36.0)$ & \\
\hline$\geq 90 \mathrm{mmHg}$ & $1,337(28.1)$ & $5,003(26.3)$ & \\
\hline Fasting blood glucose & & & $<0.001^{*}$ \\
\hline$<100 \mathrm{mg} / \mathrm{dL}$ & $2,899(60.9)$ & $12,199(64.1)$ & \\
\hline $100-125 \mathrm{mg} / \mathrm{dL}$ & $1,306(27.5)$ & $4,962(26.1)$ & \\
\hline$\geq 126 \mathrm{mg} / \mathrm{dL}$ & $553(11.6)$ & $1,871(9.8)$ & \\
\hline Total cholesterol & & & 0.538 \\
\hline$<200 \mathrm{mg} / \mathrm{dL}$ & $2,496(52.5)$ & $9,855(51.8)$ & \\
\hline $200-239 \mathrm{mg} / \mathrm{dL}$ & $1,566(32.9)$ & 6,426 (33.8) & \\
\hline$\geq 240 \mathrm{mg} / \mathrm{dL}$ & $696(14.6)$ & $2,751(14.4)$ & \\
\hline CCl score & & & $<0.001^{*}$ \\
\hline 0 & $2,708(56.9)$ & $11,966(62.9)$ & \\
\hline 1 & 887 (18.6) & $2,825(14.8)$ & \\
\hline 2 & $502(10.6)$ & $1,770(9.3)$ & \\
\hline
\end{tabular}




\begin{tabular}{|cll|}
\hline Characteristics & Total participants \\
\hline 3 & $260(5.5)$ & $889(4.7)$ \\
$\geq 4$ & $401(8.4)$ & $1,582(8.3)$ \\
\hline
\end{tabular}

Abbreviations: $\mathrm{CCl}$, Charlson comorbidity index

* Chi-square test. Significance at $\mathrm{P}<0.05$

† Obesity (BMl, body-mass index, $\mathrm{kg} / \mathrm{m}^{2}$ ) was categorized as $<18.5$ (underweight), $\geq 18.5$ to $<23$ (normal), $\geq 23$ to $<25$ (overweight), $\geq 25$ to $<30$ (obese I), and $\geq 30$ (obese II).

The sociodemographic variables between the $\mathrm{VI}$ and matched control groups are summarized in Table 1. No significant inter-group differences were found in age, sex, and baseline income level, region of residence, obesity, smoking status, SBP or total cholesterol (all P > 0.05). However, the VI group was higher DBP $(>90 \mathrm{mmHg})$, fasting blood glucose, CCI scores and less likely to have frequent alcohol consumption than the healthy controls $(\mathrm{all} P<0.05)$. 
Table 2

Difference in mean values of income between initial value and post 5-year values of visual impairment in visual impairment and control group

\section{Characteristics Paired t-test}

Interaction¥ Linear mixed modelq

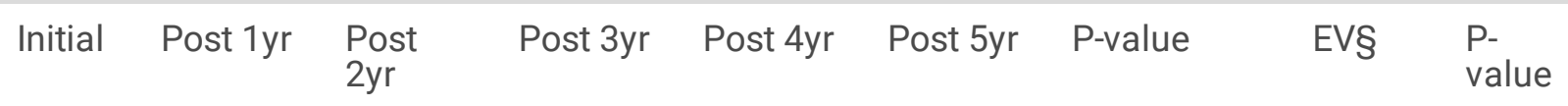

Total participants $(n=23,790)$

\begin{tabular}{|c|c|c|c|c|c|c|c|c|c|}
\hline $\begin{array}{l}\text { Visual } \\
\text { impairment } \\
\text { (mean, P- } \\
\text { value) }\end{array}$ & 5.662 & $\begin{array}{l}5.621 \\
(0.108)\end{array}$ & $\begin{array}{l}5.702 \\
(0.241)\end{array}$ & $\begin{array}{l}5.752 \\
\left(0.018^{*}\right)\end{array}$ & $\begin{array}{l}5.803 \\
(< \\
\left.0.001^{\star}\right)\end{array}$ & $\begin{array}{l}5.824 \\
(< \\
\left.0.001^{\star}\right)\end{array}$ & $0.003+$ & -0.014 & 0.771 \\
\hline $\begin{array}{l}\text { Control } \\
\text { (mean, P- } \\
\text { value) }\end{array}$ & 5.662 & $\begin{array}{l}5.776 \\
(< \\
\left.0.001^{\star}\right)\end{array}$ & $\begin{array}{l}5.853 \\
(< \\
\left.0.001^{\star}\right)\end{array}$ & $\begin{array}{l}5.865 \\
(< \\
0.001 *)\end{array}$ & $\begin{array}{l}5.946 \\
(< \\
\left.0.001^{*}\right)\end{array}$ & $\begin{array}{l}6.001 \\
(< \\
\left.0.001^{*}\right)\end{array}$ & & & \\
\hline
\end{tabular}

Age $<60$ years old, men $(n=7,645)$

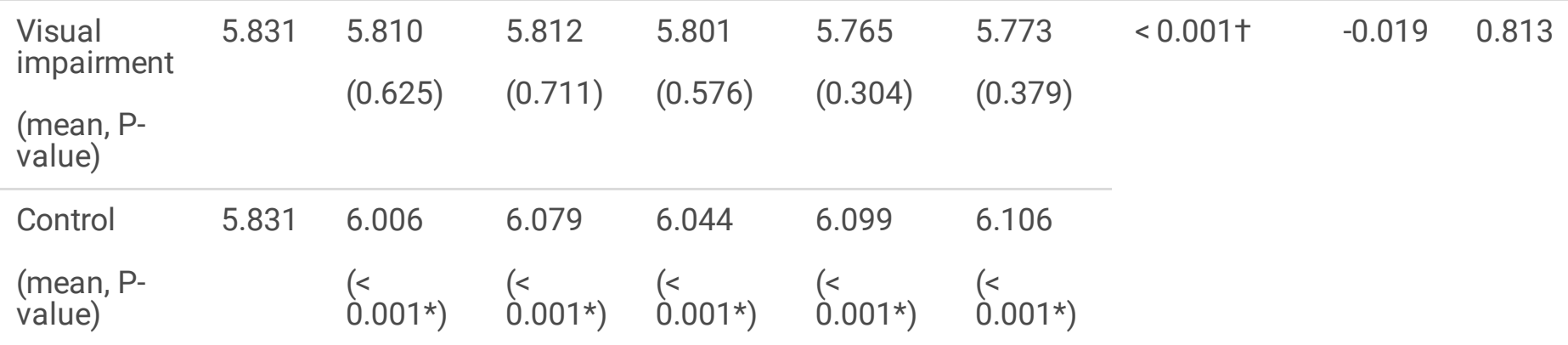

Age $<60$ years old, women $(n=3,990)$

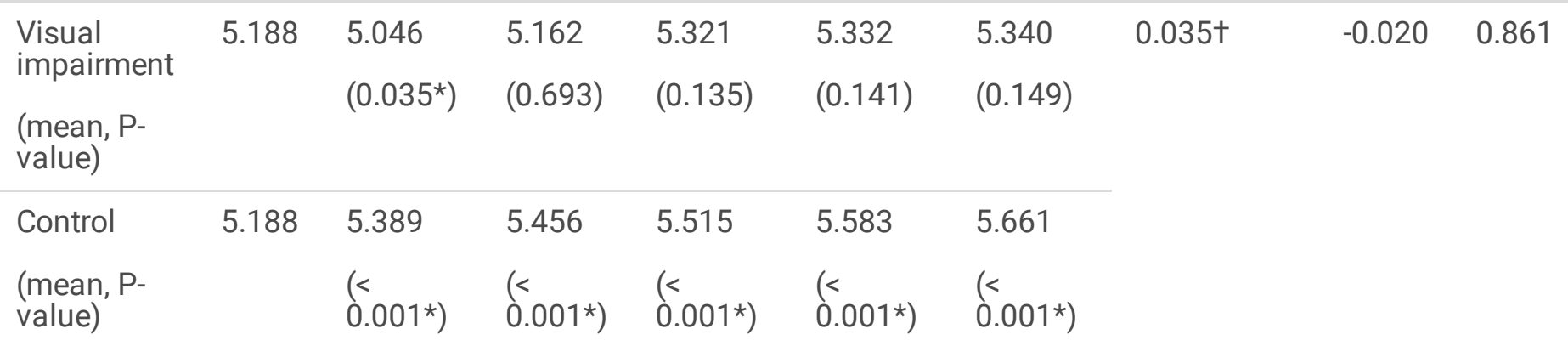

Age $\geq 60$ years old, men $(n=6,940)$

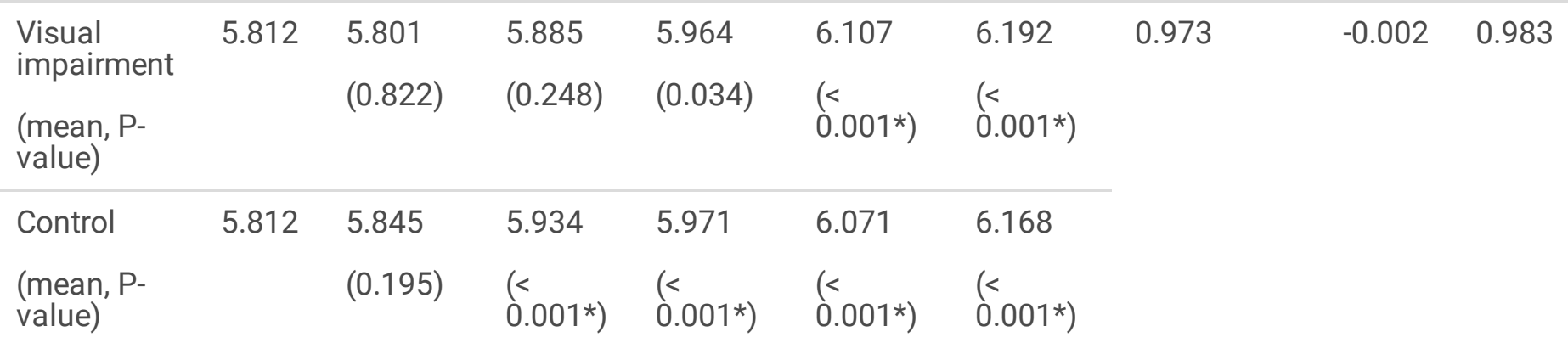

Age $\geq 60$ years old, women $(n=5,215)$ 


\begin{tabular}{|c|c|c|c|c|c|c|c|c|c|}
\hline \multirow{3}{*}{$\begin{array}{l}\text { Characteristics } \\
\begin{array}{l}\text { Visual } \\
\text { impairment } \\
\text { (mean, P- } \\
\text { value) }\end{array}\end{array}$} & \multicolumn{6}{|c|}{ Paired t-test } & \multirow{3}{*}{$\begin{array}{l}\text { Interactionł } \\
0.401\end{array}$} & \multicolumn{2}{|c|}{$\begin{array}{l}\text { Linear mixed } \\
\text { model }\end{array}$} \\
\hline & \multirow[t]{2}{*}{5.579} & 5.543 & 5.713 & 5.735 & 5.827 & 5.803 & & \multirow[t]{4}{*}{-0.005} & \multirow[t]{4}{*}{0.965} \\
\hline & & $(0.527)$ & $(0.052)$ & $(0.068)$ & $\left(0.012^{*}\right)$ & $\left(0.034^{\star}\right)$ & & & \\
\hline Control & 5.579 & 5.642 & 5.717 & 5.735 & 5.844 & 5.902 & & & \\
\hline $\begin{array}{l}\text { (mean, P- } \\
\text { value) }\end{array}$ & & $\left(0.021^{*}\right)$ & $\begin{array}{l}(< \\
0.001 *)\end{array}$ & $\begin{array}{l}(< \\
0.001 *)\end{array}$ & $\begin{array}{l}(< \\
\left.0.001^{*}\right)\end{array}$ & $\begin{array}{l}(< \\
0.001 *)\end{array}$ & & & \\
\hline
\end{tabular}

Abbreviations: EV, Estimated value; CCl, Charlson Comorbidity Index

* Paired t-test based on previous income, Significance at $\mathrm{P}<0.05$

† Linear mixed model, Significance at $\mathrm{P}<0.05$

$\ddagger$ Interaction effects between time and group

$\S$ Estimated value of linear mixed model for visual impairment group based on control group

q Fixed effects were age, sex, region of residence, visual impairment, and time of measurement. Random effects were $\mathrm{BMI}$, systolic blood pressure, diastolic blood pressure, fasting blood glucose, total cholesterol, smoking, alcohol consumption, and $\mathrm{CCl}$ scores.

Table 2 shows the changes in the mean values of income level, beginning with the initial level and proceeding over the 5 -year course of the annual follow-ups. The income levels increased according to the duration of follow-up in both the $\mathrm{VI}$ and control groups. In the $\mathrm{VI}$ group, the income levels post 3-5 years were significantly increased relative to the initial value $(P=0.018,<0.001$ and $<0.001)$, while the income levels post 1 and 2 years were not $($ all $P>0.05)$. In the control group, the income levels were increased significantly each year from post 1 year through post 5 years (all Ps $<0.001$ ). The rate of change in income between time and $\mathrm{VI}$ were significant (interaction effects, $\mathrm{P}=0.003$ ). The EV of income level for the VI group was estimated to be $-0.014(P=0.771)$.

In our subgroup analysis for age and sex, time and VI's interaction effects impacting income level were significant for the $<60$-years-old subgroups of both men and women $(P<0.001$ and 0.035$)$. The EV of income level for VI was estimated to be -0.019 and -0.020 , respectively, in these subgroups $(P=0.813$ and 0.861$)$. In the subgroup of men aged $<60$ years old, the income level of the VI group did not differ from the initial level to post 1 year through post 5 years; by contrast, it significantly increased from the initial level to post $1-5$ years (all Ps $<0.001$ ) in the control group. Similarly, in the subgroup of women $<60$ years old, the income level of the VI group decreased at post 1 year $(P=0.035)$ and did not differ thereafter, whereas the income level of the control group increased each year (post $1-5$ year, each $P<0.001$ ). The $\geq 60$-year-old men and $\geq 60$-year-old women did not show any significant interaction effects between time and $\mathrm{VI}$ for income level. 
Table 3

Difference in mean values of income between initial value and post 5-year values of visual impairment in visual impairment and control group by severity of disability

\begin{tabular}{|c|c|c|c|c|c|c|c|c|c|}
\hline \multirow[t]{2}{*}{ Characteristics } & \multicolumn{6}{|c|}{ Paired t-test } & \multirow{2}{*}{$\begin{array}{l}\text { Interaction } \neq \\
\text { P-value }\end{array}$} & \multicolumn{2}{|c|}{$\begin{array}{l}\text { Linear mixed } \\
\text { model }\end{array}$} \\
\hline & Initial & Post 1yr & $\begin{array}{l}\text { Post } \\
2 y r\end{array}$ & Post 3yr & Post 4yr & $\begin{array}{l}\text { Post } \\
5 y r\end{array}$ & & EV§ & $\begin{array}{l}\text { P- } \\
\text { value }\end{array}$ \\
\hline \multicolumn{10}{|c|}{ Mild-to-Moderate ( $n=4,170$ for visual impairment, $n=16,680$ for control) } \\
\hline \multirow{2}{*}{$\begin{array}{l}\text { Visual } \\
\text { impairment } \\
\text { (mean, P- } \\
\text { value) }\end{array}$} & \multirow[t]{2}{*}{5.688} & 5.655 & 5.733 & 5.773 & 5.823 & 5.847 & \multirow[t]{4}{*}{$0.005+$} & \multirow[t]{4}{*}{-0.016} & \multirow[t]{4}{*}{0.767} \\
\hline & & $(0.220)$ & $(0.226)$ & $(0.028 *)$ & $(0.001 *)$ & $\begin{array}{l}(< \\
0.001 *)\end{array}$ & & & \\
\hline Control & 5.688 & 5.804 & 5.883 & 5.896 & 5.976 & 6.025 & & & \\
\hline $\begin{array}{l}\text { (mean, P- } \\
\text { value) }\end{array}$ & & $\begin{array}{l}(< \\
\left.0.001^{\star}\right)\end{array}$ & $\begin{array}{l}(< \\
0.001 *)\end{array}$ & $\begin{array}{l}(< \\
\left.0.001^{*}\right)\end{array}$ & $\begin{array}{l}(< \\
\left.0.001^{\star}\right)\end{array}$ & $\begin{array}{l}(< \\
\left.0.001^{*}\right)\end{array}$ & & & \\
\hline \multicolumn{10}{|c|}{ Severe ( $\mathrm{n}=588$ for visual impairment, $n=2,352$ for control) } \\
\hline \multirow{2}{*}{$\begin{array}{l}\text { Visual } \\
\text { impairment } \\
\text { (mean, P- } \\
\text { value) }\end{array}$} & \multirow[t]{2}{*}{5.478} & 5.380 & 5.488 & 5.598 & 5.654 & 5.655 & \multirow[t]{4}{*}{0.229} & \multirow[t]{4}{*}{-0.032} & \multirow[t]{4}{*}{0.824} \\
\hline & & $(0.197)$ & & & & & & & \\
\hline Control & 5.478 & 5.598 & 5.665 & 5.664 & 5.739 & 5.821 & & & \\
\hline $\begin{array}{l}\text { (mean, P- } \\
\text { value) }\end{array}$ & & $\left(0.001^{*}\right)$ & $\begin{array}{l}(< \\
\left.0.001^{\star}\right)\end{array}$ & $\begin{array}{l}(< \\
\left.0.001^{*}\right)\end{array}$ & $\begin{array}{l}(< \\
\left.0.001^{\star}\right)\end{array}$ & $\begin{array}{l}(< \\
\left.0.001^{*}\right)\end{array}$ & & & \\
\hline
\end{tabular}

Abbreviations: EV, Estimated value; CCl, Charlson Comorbidity Index

* Paired t-test based on previous income, Significance at $\mathrm{P}<0.05$

† Linear mixed model, Significance at $\mathrm{P}<0.05$

‡ Interaction effects between time and group

$\S$ Estimated value of linear mixed model for visual impairment group based on control group

9 Fixed effects were age, sex, region of residence, visual impairment, and time of measurement. Random effects were $\mathrm{BMI}$, systolic blood pressure, diastolic blood pressure, fasting blood glucose, total cholesterol, smoking, alcohol consumption, and $\mathrm{CCl}$ scores.

According to the severity of VI, the longitudinal changes of income level were analyzed as shown in Table 3 . In the mildto-moderate $\mathrm{VI}$ group $(n=4,170)$, the income levels of post $3-5$ years were higher than the initial value $(P=0.028,<$ 0.001 and $<0.001$, respectively), while the control group showed increased income throughout the post $1-5$ years (all $P s<0.001)$. The rate of change in income between time and VI for income level was significant $(P=0.005)$, and EV of income level for VI was estimated to be $-0.016(P=0.767)$ in this subgroup. Meanwhile, the severe VI group $(n=588)$ did not show any significant interaction between time and VI for income level $(P=0.229)$.

\section{Discussion}


In this study, in order to investigate the impact of VI on longitudinal income change, health insurance data was analyzed for a large national population cohort. We performed an in-depth analysis of the effects of $\mathrm{VI}$ on income changes in both VI and matched-control groups. The income level increased in both groups over the course of 5 years, but the increase was smaller in the VI group. Although we had matched the initial income level of the $\mathrm{VI}$ and control groups, the income gap between them widened over time. The interaction of time and VI for income level was significant in a linear mixed model. A similar finding was observed in a subgroup analysis of $<60$-year-old participants.

Although there have been a few studies on VI and income level to date $6,13,15,16$, the economic consequences of $\mathrm{VI}$ have rarely been evaluated in representative samples of national populations. Also, the present study's longitudinal design contrasts with the majority of studies published thus far, which have been of cross-sectional design ${ }^{3,4,6,14,17}$. The results of cross-sectional studies typically have limited implications due to the lack of temporality of risk factor data; this means that the causal relationship between, for example, VI and income level, would have to be interpreted with caution. The present study, on the other hand, using the linear mixed model, was able to prove the interaction of time and VI for income level.

As is consistent with the fact that income and real-estate assets generally increase with age ${ }^{18-20}$, our results showed that income level increased in both the control and VI groups. The finding of income growth, in itself, in the VI group might be taken as an encouraging result. However, the rate of increase in income level was, characteristically, lower than that of the control group. Moreover, most of the VI group may well have had a lower baseline income compared with the control; indeed, several cross-sectional studies have noted low baseline income for VI relative to non-VI individuals $5,21,22$. And although we included initial-income-matched control participants, income growth was lower in the VI group. This is indicative of a wider gap in total income/assets between the VI and control groups in the real world.

As could be expected, individuals with VI are known to have less economic capacity. Brezin et al. ${ }^{13}$ found monthly household incomes to be lower for the low vision (€1255) and blindness (€1587) groups than for those having no visual problems (€1851). In Britain, the risk of poor vision has been associated with social class (i.e., unskilled manual workers) ${ }^{23}$. People suffering VI have been deemed to be at greater risk of unemployment, permanent disability, being a member of the working class, lacking skills-development opportunity, being less recognized for their work, and earning an inadequate income ${ }^{24}$.

Aging by itself is a source of disability and a universal risk factor associated with VI. Rates of VI and blindness have been documented to increase sharply with age, beginning at about 65 to 70 years ${ }^{22,25,26}$. In the present study, the effect of age on income change was adjusted for by subdividing and analyzing age based on the age of 60 . Even after this adjustment, under the age of 60 , both men and women showed a greater increase of income in the control group than in the $\mathrm{VI}$ group. Interestingly, for those over the age of 60 , contrastingly, income change over time between the $\mathrm{VI}$ group and the control group was not significant. The younger age group, certainly, would be expected to be economically more active than the older age group. Therefore, for them, the impact of $\mathrm{VI}$ on employment status, working performance and income level could be especially strong. More research is needed to assess whether such income differences as shown in our under- 60 group between $\mathrm{VI}$ sufferers and non-VI individuals can be explained by other socioeconomic differences.

In present study, income changes also were analyzed according to severity of VI. In the mild-to-moderate group ( $\mathrm{n}=$ 4,170 for $\mathrm{VI}$ ), most of the study subjects showed an interaction effect between time and VI for income level. However, the severe $\mathrm{VI}$ group $(\mathrm{n}=588$ for $\mathrm{VI}$ ) showed no significant income-change differences over time. We considered that the relatively small size of the severe VI group was insufficient to secure the statistical power.

In addition to visual function, educational level and SES also interact with each other ${ }^{2-7,12}$. VI, educational level, and SES act in similar though different ways to produce low income levels. That is, the effect of an individual's VI on his/her 
income change might not be direct only, but might also emerge from other, intermediary and perhaps complex determinants that remain, pending investigation.

There are some limitations to this study. First, limitations of available data precluded us from considering the leading causes of VI. Due to the study design's use of KNHIS data, there was no specific data on VI causes. In epidemiological investigations, the major cause of VI has been mostly age-related macular degeneration in developed countries, and

cataract in under-developed countries ${ }^{27-30}$. Analysis of the causes of VI could help to understand economic inequality caused by VI. Second, selection bias may have influenced our results. The use of registers to estimate VI prevalence is in any case controversial, since a high proportion of subjects thus impaired do not register ${ }^{31,32}$. Moreover, in Korea, application for registration of disability is directly made by the individual him/herself; and there is a strong possibility that a high proportion of VI persons who do register are those who experience economic difficulty. Finally, in this study, low vision and blindness were included together and analyzed as $\mathrm{VI}$, but the economic disparity between subjects with "low vision" and "blindness" was far greater than what we expected.

Despite these limitations, this study reports, based on a longitudinal database, nationwide estimates of how VI affects income change according to subject age and severity of VI. We showed that in a large representative sample of Korea, the growth in the income level of the VI group was less than that of a control group matched for age, sex, region of residence and income level. Although additional research is needed to more thoroughly elucidate and target the drivers of disparity, our findings identify areas requiring improvement for people with VI. Based on these data, a specific nationwide database for the SES of VI could be compiled, and in turn, policies would be formulated to provide the most appropriate financial and social assistance.

\section{Methods}

This study was authorized by the Ethics Committee of Hallym University (2019-10-023). Written informed consent was waived by the Institutional Review Boards of Hallym University Sacred Heart Hospital. In all of the analyses, the Ethics Committee guidelines and regulations were strictly adhered to. In Korea, a representative sample cohort database comprising approximately one million people has been provided by the KNHIS. The database includes medical care histories listed by diagnostic/treatment codes, socioeconomic data, life and death information, and individual disability over a period ranging from 2002 to $2015^{33-35}$.

\section{Definition of Visual impairment}

Participants found to have VI where those who had registered as VI persons at the Ministry of Health and Welfare. We excluded those with co-disabilities. In Korea, legal VI is defined as the presence of any of the following 4 conditions that show stabilization after at least 6 months of treatment and are not reversed by medication or surgery: 1) best-corrected visual acuity (BCVA) $\leq 20 / 1000$ in the worse eye, 2) BCVA $\leq 20 / 100$ in the better eye, 3) a binocular visual field $<1 / 2$, and 4) visual field $\leq 10^{\circ}$ from the visual axis for both eyes. The patient must submit a medical certificate issued by an ophthalmologist regarding the BCVA, visual field, and the possible reason for VI before being registering as visually impaired. With properly documented evidence of a $\mathrm{VI}$, an assessment committee discusses the feasibility of the $\mathrm{VI}$ registration. In Korea, the degree of VI is typically divided into 6 grades according to the its severity; in the database, the data are then divided into two grades (mild-to-moderate VI group, grades III-Vl; severe VI group, grades I-II).

\section{Definition of Income}

Income level was divided into deciles of population based on KNHIS annual premiums (Supplementary Table 1). Medical Aid beneficiaries were added to the lowest income level ${ }^{36}$. Income change for participants was defined as an 
income-level change between the income prior and closest to the day of VI registration and the income 5 years after that.

\section{Participant Selection}

The VI group was selected from 514,866 participants for whom $615,488,428$ medical claim codes had been registered between the years 2002 and $2015(n=5,292)$. The control group was compiled of participants not defined as VI during the years 2002 through $2015(n=509,574)$. VI participants diagnosed with other disabilities $(n=77)$ or with VI after 2011 ( $n=457$ ) were excluded. VI participants were matched with participants (control group) who had never been diagnosed with a VI or other disabilities from 2002 through 2015. Control participants were excluded if they had been diagnosed with disabilities $(n=45,081)$. VI participants were 1:4 matched with control participants for age, sex, initial income on index date, and region of residence. The participants serving as the control were randomly selected in order

to minimize selection bias. The index date of each VI participant was set as the time of diagnosis of VI. The index date of each control participant was set as the index date of the matched VI participant. Therefore, each VI/control participant matched pair had the same index date. During the matching procedure, 445,461 control participants were excluded. Ultimately, 4,758 VI participants were 1:4 matched with 19,032 control participants (Fig. 1).

\section{Covariates}

The following ten age groups were formed: $40-44,45-49,50-54 \ldots, 80-84$, and $85+$ years old. Residence regions were grouped into urban (Seoul, Busan, Daegu, Incheon, Daejeon, Gwangju, Ulsan) and rural (Gangwon, Gyeonggi, Chungcheongbuk, Chungcheongnam, Gyeongsangbuk, Gyeongsangnam, Jeollabuk, Jeollanam, Jeju) areas.

Tobacco smoking was classified based on the current smoking status (current smoker, past smoker, and nonsmoker) of participants. Alcohol consumption was categorized based on its frequency ( $\geq 1$ time a week and $<1$ time a week). Obesity was determined according to body-mass index (BMI, $\left.\mathrm{kg} / \mathrm{m}^{2}\right)$, BMI having been categorized as follows: $<18.5$ (underweight), $\geq 18.5$ to $<23$ (normal), $\geq 23$ to $<25$ (overweight), $\geq 25$ to $<30$ (obese I), and $\geq 30$ (obese II), based on the Asia-Pacific criteria of the Western Pacific Regional Office (WPRO) $2000^{37}$. Also investigated were systolic blood pressure (SBP) and diastolic blood pressure (DBP) along with fasting blood glucose and total cholesterol. Missing BMI (23/23,790 [0.097\%]), SBP (17/23,790 [0.071\%]), DBP (17/23,790 [0.071\%]), fasting blood glucose (31/23,790 [0.130\%]), and total cholesterol $(48 / 23,790[0.202 \%])$ values were replaced by the mean values of each variable for the final selected participants.

The Charlson Comorbidity Index (CCI) has been used widely to measure disease burden according to 17 comorbidities. The CCl score is reflective of disease severity and number both, and is recorded as a continuous variable (range: 0 [no comorbidities] -29 [multiple comorbidities]) ${ }^{38,39}$.

\section{Statistical Analyses}

The differences in the rates of the general characteristics were compared using the Chi-square test. The differences in the mean values of income between the initial index date and the 5-years-post-VI-registration date were compared using the paired t-test.

To estimate the interaction and estimated value (EV) of repeated measures data, a linear mixed model was used. Age, sex, region of residence, $\mathrm{VI}$, and time of measurement were used as the independent variables and fixed effects. BMI, SBP, DBP, fasting blood glucose, total cholesterol, smoking, alcohol consumption, and CCI scores were used as random effects. A first-order autoregressive model was selected as the repeated covariance type, considering the correlation of each participant's iteration. The statistical analysis model of the linear mixed model is as follows:

Page $11 / 15$ 
$Y_{i}=X_{i 1} \beta_{1}+\ldots+X_{i p} \beta_{p}+Z_{i 1} \mathrm{u}_{i}+\ldots+Z_{i \mathrm{q}} \mathrm{u}_{q}+e_{i}$, for all $i=1, \ldots, n$

with $Y=\left(Y_{1}, \ldots, Y_{n}\right)^{\prime}, \mathrm{X}$ the $n \times p$ matrix of covariates with fixed effects $\beta=\left(\beta_{1}, \ldots, \beta_{p}\right)^{\prime}$,

$\mathrm{Z}$ the $n \times q$ matrix of covariates with random effects $\mathrm{u}=\left(u_{1}, \ldots, u_{q}\right)^{\prime} \sim \mathrm{N}\left(0, \tau I_{q}\right)$, and the

residual error vector $e=\left(e_{1}, \ldots, e_{n}\right)^{\prime} \sim \mathrm{N}\left(0, \tau I_{n}\right)$,

In the subgroup analyses, we subdivided the participants according to age and sex ( $<60$ years old and $\geq 60$ years old; men and women). According to severity, VI was divided into mild-to-moderate VI and severe VI groups.

We performed two-sided analyses and determined statistical significance based on $\mathrm{P}$ values $<0.05$. SAS version 9.4 (SAS Institute Inc., Cary, NC, USA) was used in the analyses.

\section{Declarations}

\section{ACKNOWLEDGEMENTS}

None

\section{AUTHOR CONTRIBUTIONS}

Conceptualization (H.G.C., M.J.L., S.U.B.); Data curation (H.G.C., M.J.L., S.U.B.); Formal analysis (H.G.C.); Methodology (H.G.C., M.J.L., S.U.B.); Writing - original draft (M.J.L., S.U.B.); Writing - review \& editing (H.G.C., M.J.L., S.U.B.)

\section{DATA AVAILABILITY}

Data supporting the findings of the current study are available from the corresponding author on reasonable request.

\section{References}

1. Fouad, D., Mousa, A. \& Courtright, P. Sociodemographic characteristics associated with blindness in a Nile Delta governorate of Egypt. British Journal of Ophthalmology. 88, 614-618 (2004).

2. Ho, V. H. \& Schwab, I. R. Social economic development in the prevention of global blindness. British Journal of Ophthalmology. 85, 653-657 (2001).

3. Dandona, R. \& Dandona, L. Socioeconomic status and blindness. British journal of ophthalmology. 85, 1484-1488 (2001).

4. Bailey, R. et al. Visual impairment and eye care among older adults-five States, 2005. MMWR. Morbidity and mortality weekly report. 55, 1321-1325 (2006).

5. Frick, K. D., Gower, E. W., Kempen, J. H. \& Wolff, J. L. Economic impact of visual impairment and blindness in the United States. Archives of Ophthalmology. 125, 544-550 (2007).

6. Wilson, C. J., Rust, G., Levine, R. \& Alema-Mensah, E. Disparities in vision impairment among adults in the United States. Ethn Dis. 18, S2-242 (2008).

7. Evans, T. Socioeconomic consequences of blinding onchocerciasis in west Africa. Bulletin of the World health organization. 73, 495 (1995). 
8. Mathenge, W. et al. Rapid assessment of avoidable blindness in Nakuru district, Kenya. Ophthalmology. 114, 599605 (2007).

9. Wadud, Z. et al. Rapid assessment of avoidable blindness and needs assessment of cataract surgical services in Satkhira District, Bangladesh. British Journal of Ophthalmology. 90, 1225-1229 (2006).

10. Eusebio, C. et al. Rapid assessment of avoidable blindness in Negros Island and Antique District, Philippines. British Journal of Ophthalmology. 91, 1588-1592 (2007).

11. Dandona, L. et al. Blindness in the Indian state of Andhra Pradesh. Investigative ophthalmology \& visual science. 42, 908-916 (2001).

12. Ulldemolins, A. R., Lansingh, V. C., Valencia, L. G., Carter, M. J. \& Eckert, K. A. Social inequalities in blindness and visual impairment: a review of social determinants. Indian journal of ophthalmology. 60, 368 (2012).

13. Brézin, A. P., Lafuma, A., Fagnani, F., Mesbah, M. \& Berdeaux, G. Prevalence and burden of self-reported blindness, low vision, and visual impairment in the French community: a nationwide survey. Archives of ophthalmology. 123, 1117-1124 (2005).

14. Liu, J. H., Cheng, C. Y., Chen, S. J. \& Lee, F. L. Visual impairment in a Taiwanese population: prevalence, causes, and socioeconomic factors. Ophthalmic epidemiology. 8, 339-350 (2001).

15. Ryskulova, A. et al. Self-reported age-related eye diseases and visual impairment in the United States: results of the 2002 national health interview survey. American journal of public health. 98, 454-461 (2008).

16. Stang, A. \& Jöckel, K. H. Visual disturbances in a population-based survey of 6962 subjects: the German National Health Examination Survey 1998. The European Journal of Public Health. 13, 202-209 (2003).

17. Murthy, G. V. S., Gupta, S., Bachani, D. \& Jose, R. \& John, N. Current estimates of blindness in India. British Journal of Ophthalmology. 89, 257-260 (2005).

18. Costa-Font, J. Housing assets and the socio-economic determinants of health and disability in old age. Health \& place. 14, 478-491 (2008).

19. Peterson, M. Effects of income, assets and age on the vacationing behavior of US consumers. Journal of Vacation Marketing. 13, 29-43 (2007).

20. Waldegrave, C. \& Cameron, M. Income, assets, living standards and housing. Enhancing wellbeing in an ageing society,65-84(2009).

21. Kuper, H. et al. A case-control study to assess the relationship between poverty and visual impairment from cataract in Kenya, the Philippines, and Bangladesh. PLoS Med. 5, e244 (2008).

22. Tielsch, J. M., Sommer, A., Witt, K., Katz, J. \& Royall, R. M. Blindness and visual impairment in an American urban population: the Baltimore Eye Survey. Archives of ophthalmology. 108, 286-290 (1990).

23. Rahi, J. S., Cumberland, P. M. \& Peckham, C. S. Visual function in working-age adults: early life influences and associations with health and social outcomes. Ophthalmology. 116, 1866-1871 (2009).

24. Mojon-Azzi, S. M., Sousa-Poza, A. \& Mojon, D. S. Impact of low vision on employment. Ophthalmologica. 224, 381388 (2010).

25. Klein, R., Klein, B. E., Linton, K. L. \& De Mets, D. L. The Beaver Dam eye study: visual acuity. Ophthalmology. 98, 1310-1315 (1991).

26. Zhao, J., Jia, L., Sui, R. \& Ellwein, L. B. Prevalence of blindness and cataract surgery in Shunyi County, China. American journal of ophthalmology. 126, 506-514 (1998).

27. Abou-Gareeb, I., Lewallen, S., Bassett, K. \& Courtright, P. Gender and blindness: a meta-analysis of population-based prevalence surveys. Ophthalmic epidemiology. 8, 39-56 (2001). 
28. Klein, R., Wang, Q., Klein, B., Moss, S. E. \& Meuer, S. M. The relationship of age-related maculopathy, cataract, and glaucoma to visual acuity. Investigative ophthalmology \& visual science. 36, 182-191 (1995).

29. Wang, J. J., Foran, S. \& Mitchell, P. Age-specific prevalence and causes of bilateral and unilateral visual impairment in older Australians: the Blue Mountains Eye Study. Clinical \& experimental ophthalmology. 28, 268-273 (2000).

30. Dineen, B. et al. Causes of blindness and visual impairment in Pakistan. The Pakistan national blindness and visual impairment survey. British journal of ophthalmology. 91, 1005-1010 (2007).

31. Robinson, R. et al. Unrecognised and unregistered visual impairment. British Journal of Ophthalmology. 78, 736740 (1994).

32. Wormald, R. \& Evans, J. Registration of blind and partially sighted people. The British journal of ophthalmology. 78, 733 (1994).

33. Choi, H. G., Lee, M. J. \& Lee, S. M. Visual impairment and risk of depression: A longitudinal follow-up study using a national sample cohort. Scientific reports. 8, 1-8 (2018).

34. Choi, H. G., Lee, M. J. \& Lee, S. M. Mortality and causes of death in a population with blindness in Korea: A longitudinal follow-up study using a national sample cohort. Scientific reports. 10, 1-9 (2020).

35. Kim, S. Y., Min, C., Oh, D. J. \& Choi, H. G. Tobacco Smoking and Alcohol Consumption Are Related to Benign Parotid Tumor: A Nested Case-Control Study Using a National Health Screening Cohort. Clinical and experimental otorhinolaryngology. 12, 412 (2019).

36. National Health Insurance Service-National Medical Examination Sample Cohort (NHIS-NMES) User manual. Available at https://nhiss.nhis.or.kr/bd/ab/bdaba006cv.do [accessed January 20, 2017].

37. WHO/IASO/IOTR. The Asia-Pacific Perespective: Redefining Obesity and its Treatment (Health Communications Australia Pty Ltd, 2000).

38. Quan, H. et al. Practice of epidemiology: updating and validating the Charlson comorbidity index and score for risk adjustment in hospital discharge abstracts using data from 6 countries. Am J Epidemiol. 173, 676-682 (2011).

39. Quan, H. et al. Coding algorithms for defining comorbidities in ICD-9-CM and ICD-10 administrative data.Medical care,1130-1139(2005).

\section{Figures}




\section{Overview of the study}

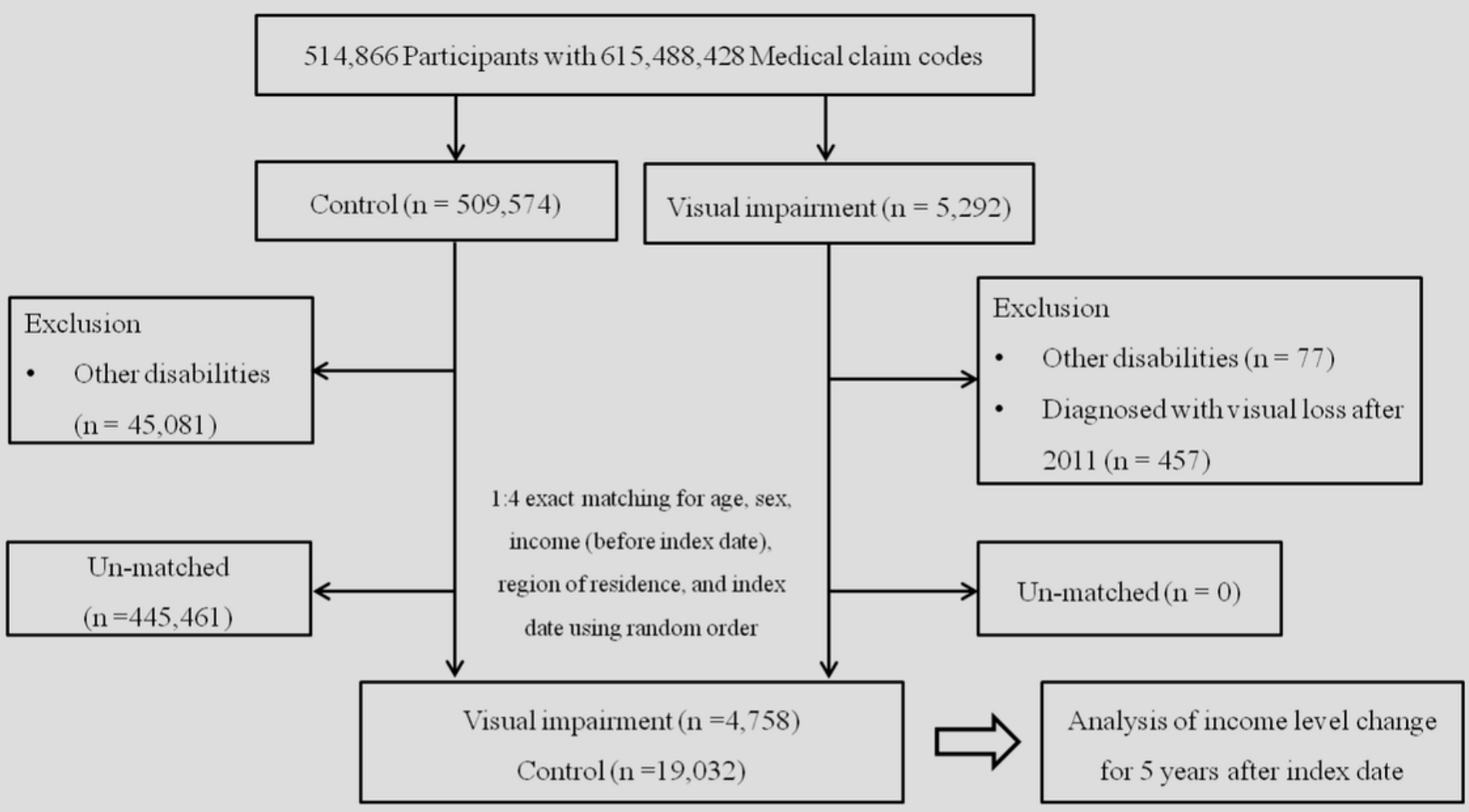

\section{Statistics}

- $\quad$ Paired T-test

- $\quad$ Linear mixed model

- Fixed effect: Age, sex, region of residence, visual loss, and time of measurement

- Random effect: BMI, fasting blood glucose, smoking, alcohol consumption, and CCI scores
Results

- Pre index date income level matching

- Increase of income level in both visual impairment and control participants over time

- Greater increase of income level in control participants rather than visual impairment participants

\section{Figure 1}

Schematic illustration of participant selection process used in present study. Among a total of 514,866 participants, 4,758 visual impairment ( $\mathrm{VI}$ ) participants were 1:4 matched with 19,032 control participants for age, sex, income level, region of residence and obesity.

\section{Supplementary Files}

This is a list of supplementary files associated with this preprint. Click to download.

- SupplementaryTable1.docx 